\title{
[HMIM][Br9]: a Room-temperature Ionic Liquid Based on a Polybromide Anion
}

\author{
Heike Haller ${ }^{\mathrm{a}}$, Michael Hog ${ }^{\mathrm{a}}$, Franziska Scholz ${ }^{\mathrm{a}}$, Harald Scherer ${ }^{\mathrm{a}}$, Ingo Krossing ${ }^{\mathrm{a}}$, and \\ Sebastian Riedel ${ }^{\mathrm{a}, \mathrm{b}}$ \\ a Albert-Ludwigs Universität Freiburg, Institut für Anorganische und Analytische Chemie, \\ Albertstrasse 21, 79104 Freiburg, Germany \\ ${ }^{\mathrm{b}}$ Freie Universität Berlin, Institut für Chemie und Biochemie, Fabeckstrasse 34-36, 14195 \\ Berlin, Germany \\ Reprint requests to Sebastian Riedel. E-mail: sriedel@psichem.de or Ingo Krossing. \\ E-mail: ingo.krossing@ac.uni-freiburg.de
}

Z. Naturforsch. 2013, 68b, 1103 - 1107 / DOI: 10.5560/ZNB.2013-3143

Received June 4, 2013

$\left[\right.$ HMIM] $\left[\mathrm{Br}_{9}\right]$ ([HMIM] = 1-hexyl-3-methylimidazolium) has been investigated by Raman spectroscopy, single-crystal X-ray diffraction and NMR spectroscopy. Conductivity measurements show a high electrical conductivity like other polybromides.

Key words: Ionic Liquids, Polybromide Anions, Halogen Chemistry, Single-crystal X-Ray Diffraction, Raman Spectroscopy

\section{Introduction}

In recent years polyhalogen chemistry has again attracted the attention of the chemical community. Several fundamental new polyhalides have been prepared and characterized. Among these, the polybromide anions have shown the largest variety. Especially our knowledge about dianions was vastly expanded due to the structures of $\left[\mathrm{Br}_{8}\right]^{2-}[1],\left[\mathrm{Br}_{10}\right]^{2-}[2],\left[\mathrm{Br}_{20}\right]^{2-}[3,4]$ or of polybromide networks [3,5-7] like $\left[\left(\mathrm{Br}_{3}\right)^{-}\left(1 / 2 \mathrm{Br}_{2}\right)\right]$, $\left[\left(\mathrm{Br}^{-}\right)_{2}\left(\mathrm{Br}_{4}\right)^{2-}\right]$, and $\left[\left(\mathrm{Br}^{-}\right)_{2}\left(\mathrm{Br}_{2}\right)_{3}\right]$. In the case of polybromide monoanions only $\left[\mathrm{Br}_{3}\right]^{-}$has been fully characterized, including the single-crystal structure of one of its salts $[1,8,9]$. Beyond this, no structural data of a higher polybromide monoanion was known prior to our reports in recent years. Based on new synthetic strategies in either ionic liquids (ILs) [10] or in neat halogens [11] several compounds with polybromide monoanions have been prepared and were further characterized in the last two years [12]. In 2011 our group reported the first preparation and structural characterization of a higher polybromide monoanion $\left[\mathrm{NPr}_{4}\right]\left[\mathrm{Br}_{9}\right]$ [11] several variations of which have been prepared in the meantime [13]. Afterwards Feldmann et al. reported the synthesis and characterization of $\left[\mathrm{PPh}_{3} \mathrm{Br}\right]\left[\mathrm{Br}_{7}\right][14]$ in ionic liquids, and Himmel et al. reported the structure of a $\left[\mathrm{Br}_{5}\right]^{-}$salt [15]. Very recently we were able to prepare and crystallographically analyze the so far highest representative of a polyhalogen monoanion, the undecabromide [PPN] $\left[\mathrm{Br}_{11} \cdot \mathrm{Br}_{2}\right]$ (PPN = bis(triphenylphosphine)iminium) [16]. Today, we know the crystal structures of compounds of the entire series of polybromide monoanions from $\left[\mathrm{Br}_{3}\right]^{-}$ to $\left[\mathrm{Br}_{11}\right]^{-}$. Along with their structural characterization, the physical properties of these novel substances have partly been investigated as well. The most surprising property was found for the nonabromide monoanions, which show extremely high electrical conductivities for the row of quaternary ammonia salts $\left[\mathrm{NR}_{4}\right]\left[\mathrm{Br}_{9}\right]$ ( $\mathrm{R}=\mathrm{Me}, \mathrm{Et}, \mathrm{Pr}, \mathrm{Bu})$ [13].

Here, we report the first preparation of a roomtemperature ionic liquid based on a nonabromide monoanion, namely $[\mathrm{HMIM}]\left[\mathrm{Br}_{9}\right] \quad([\mathrm{HMIM}]=1-$ hexyl-3-methylimidazolium), which was characterized by single-crystal X-ray diffraction and Raman spectroscopy. Furthermore, as for the known nonabromide anions stabilized by quaternary ammonia salts, we also investigated its temperature-dependent electrical conductivity. 


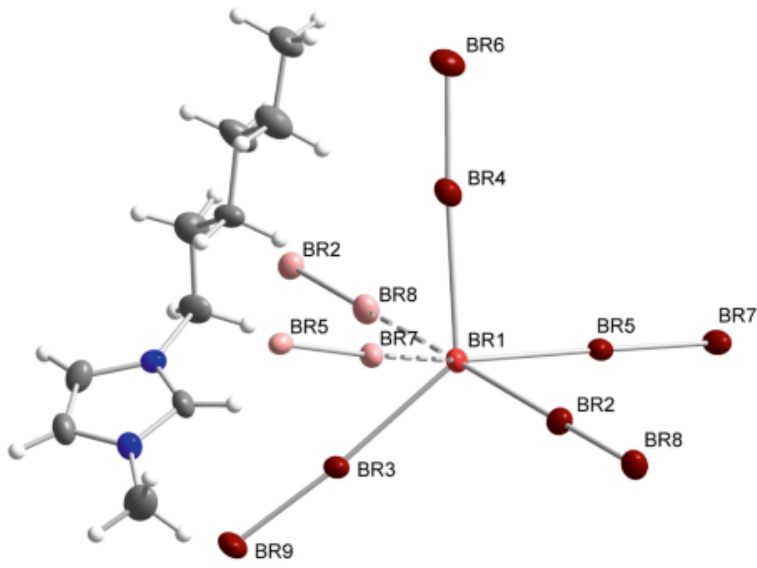

Fig. 1. Molecular structure of $[\mathrm{HMIM}]\left[\mathrm{Br}_{9}\right]$ in the crystal. Displacement ellipsoids are drawn at the $50 \%$ probability level.

\section{Results and Discussion}

The reaction of [HMIM]Br ([HMIM] = 1-hexyl-3methylimidazolium) with an excess of bromine led to the room-temperature ionic liquid [HMIM] $\left[\mathrm{Br}_{9}\right]$. After several weeks at $-40{ }^{\circ} \mathrm{C}$ brownish-red crystals were obtained.

\section{Crystal and molecular structure}

The single-crystal X-ray structure determination of [HMIM][Br9] (1) has shown that the salt crystallizes in the orthorhombic space group $P 2{ }_{1} 2_{1} 2_{1}$ with $Z=4$. In analogy to other polyhalide monoanions the $\left[\mathrm{Br}_{9}\right]^{-}$ structure is built up of the two building blocks, $\mathrm{Br}_{2}$ and $\mathrm{Br}^{-}$(Fig. 1). The central bromide anion is end-on coordinated by six bromine molecules resulting in two sets of $\mathrm{Br}^{-}-\left(\mathrm{Br}_{2}\right)$ distances: 4 shorter interactions in the range from 290.8 to 306.4 pm (av.: $298.9 \mathrm{pm}$ ) and two longer secondary interactions at 326.9 and $347.0 \mathrm{pm}$. Four of the $\mathrm{Br}_{2}$ moieties are asymmetrically bridging two bromide ions thereby forming a $2 \mathrm{D}\left[\mathrm{Br}_{9}\right]^{-}$layer.

Compared to neat solid $\mathrm{Br}_{2}(228.1 \mathrm{pm})$ [17] the bond lengths of the coordinated $\mathrm{Br}_{2}$ molecules are elongated by more than $5 \mathrm{pm}$, see Table 1 . This is in agreement with previous observations and mainly due to the charge donation of the central bromide into the LUMO of the coordinated $\mathrm{Br}_{2}$ Lewis acid [11, 13, 16]. Usually the coordination of the $\mathrm{Br}_{2}$ molecules occurs with an almost $180^{\circ}$ angle as it is also observed in the present structure $\left(173.1-177.9^{\circ}\right)$. However, the bond
Table 1. Bond lenghts found in the molecular structure of [HMIM][Br9].



Fig. 2. Projection of the network of $\mathbf{1}$. In this crystal structure the $\left[\mathrm{Br}_{9}\right]^{-}$units are linked to layers.

angle of $(\mathrm{Br} 1, \mathrm{Br} 7, \mathrm{Br} 5)$ marks an exception with its smaller value of $161.9^{\circ}$.

It is worth comparing the assembly of this structure (Fig. 2) to that of the closely analogous quaternary ammonium salts of the form $\left[\mathrm{NR}_{4}\right]\left[\mathrm{Br}_{9}\right](\mathrm{R}=\mathrm{Me}, \mathrm{Et}$, $\mathrm{Pr}$, $\mathrm{Bu})$.

\section{Raman spectroscopy}

[HMIM][Br 9$]$ shows two intense Raman lines at 279 and $269 \mathrm{~cm}^{-1}$. This is in accordance with previous observations of Raman lines in the range between 300 and $250 \mathrm{~cm}^{-1}$ for nonabromide monoanions, and also in agreement with the results of our quantumchemical calculations at SCS-MP2 level. Nevertheless, the corresponding $\mathrm{T}_{2}$ mode is shifted by approximately $10 \mathrm{~cm}^{-1}$ compared to $\left[\mathrm{NEt}_{4}\right]\left[\mathrm{Br}_{9}\right]$ or $\left[\mathrm{NPr}_{4}\right]\left[\mathrm{Br}_{9}\right]$. This may be ascribed to the different cation/anion interactions, see Table 2. The Raman spectrum is shown in the Supporting Information available online (see the note at the end of the paper for availability). Due to the higher tendency to lose elemental bromine of the herein reported salts, IR spectra were not recorded. 
Table 2. Comparison of the experimental and computed Raman lines.

\begin{tabular}{lllc}
\hline & & \multicolumn{2}{c}{ Wavenumber $\left(\mathrm{cm}^{-1}\right)$} \\
\cline { 2 - 4 } & Symmetry & exp. & calcd. $^{\text {a }}$ \\
\hline$\left[\right.$ HMIM] $\left[\mathrm{Br}_{9}\right]$ & $\mathrm{A}_{1}$ & 279 & 277 \\
& $\mathrm{~T}_{2}$ & 269 & 255 \\
\hline
\end{tabular}

a RI-MP2/def2-TZVPP-Niveau [13].

\section{Conductivity}

As mentioned before the salts with nonabromide anions show unusually high electrical conductivities. Normally, ionic liquids based on imidazolium cations show conductivities in the range of 1 to $10 \mathrm{mS} \mathrm{cm}^{-1}$ at $25^{\circ} \mathrm{C}[18,19]$. In line with this observation the compound under investigation also exhibits an exceptionally high conductivity of, $e . g ., 52.1 \mathrm{mS} \mathrm{cm}^{-1}$ at $25.6^{\circ} \mathrm{C}$. Fig. 3 shows the conductivities between 10 and $60^{\circ} \mathrm{C}$. A table of the numerical values is given in the Supporting Information. For comparison: at $26.6^{\circ} \mathrm{C}$ the parent $\mathrm{Br}_{2}$-free compound [HMIM]Br has an almost negligble conductivity of $54.2 \mu \mathrm{S} \mathrm{cm}^{-1}$.

Like for other ILs the temperature dependence of the conductivity is well described by a VogelFulcher-Tammann behavior [18]. The Vogel temperature, which is the ideal glass transition temperature of $190( \pm 8) \mathrm{K}$, is in the range of other good RT$\mathrm{ILs}$, e. $g$. those with the classical $\left[\mathrm{N}\left(\mathrm{SO}_{2} \mathrm{CF}_{3}\right)_{2}\right]^{-}$an-

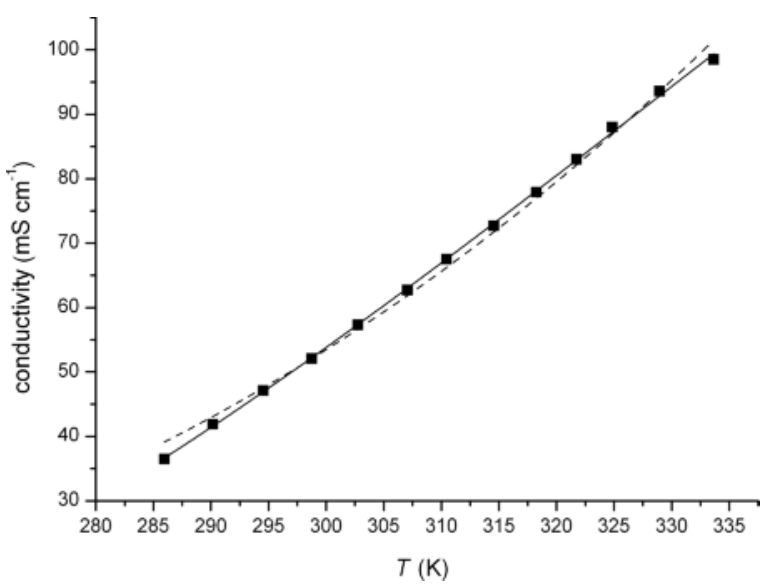

Fig. 3. Temperature-dependent electrical conductivity analyzed with respect to Arrhenius (dashed line, $\sigma=$ $A_{\sigma} \mathrm{e}^{-E / \mathrm{R} T}, \quad A_{\sigma}=30810( \pm 4320), \quad E=15900( \pm 375)$ $\mathrm{J} \mathrm{mol}^{-1}$ ) and Vogel-Fulcher-Tammann (continuous line, $\sigma=A_{\sigma} \mathrm{e}^{-k /\left(T-T_{0}\right)}, A_{\sigma}=733( \pm 117), k=286( \pm 38) \mathrm{K}^{-1}$, $\left.T_{0}=190( \pm 8) \mathrm{K}\right)$ behavior. ion [18]. Nevertheless, the temperature dependence can also be described adequately by the Arrhenius approach. The activation energy was determined to be $16( \pm 4) \mathrm{kJ} \mathrm{mol}^{-1}$.

As suggested in previous conductivity investigations of the $\mathrm{Br}^{-} / \mathrm{Br}_{2}$ system the high conductivity is possibly due to a Grotthuss-type hopping mechanism [20]. This hopping mechanism is also expected for the present system [HMIM] $\left[\mathrm{Br}_{9}\right]$ as shown in Eq. (1).

$$
\begin{aligned}
& {\left[\mathrm{Br}_{9}\right]^{-}+\mathrm{Br}^{-} \rightarrow \mathrm{Br}^{-}-\mathrm{Br}_{8} \cdots \mathrm{Br}^{-}} \\
& \rightarrow \mathrm{Br}^{-} \cdot \mathrm{Br}_{8}-\mathrm{Br}^{-} \rightarrow \mathrm{Br}^{-}+\left[\mathrm{Br}_{9}\right]^{-}
\end{aligned}
$$

In view of its slightly lower conductivity, when compared with the quaternary ammonia salts, the main advantage of the present system is based on its liquid nature at room temperature. This will potentially permit its application as a liquid redox-active electrode.

\section{NMR measurements}

According to Spange et al. [21] the chemical shift of the hydrogen atom at the C-2 position of the imidazolium ring is dependent on the interaction of the cation with the anion. In diluted solutions of different imidazolium salts in dichloromethane they found the resonance of this hydrogen atom shifted to higher field the weaker these $\mathrm{C}-2-\mathrm{H} \cdots \mathrm{X}$ interactions are. In contrast to Spange et al., we investigated in our case the pure ionic liquids and compared the proton NMR spectra of [HMIM] Br and [HMIM] $\left[\mathrm{Br}_{9}\right]$. A table of the numerical values and figures of the respective ${ }^{1} \mathrm{H}$ NMR spectra are given in the Supporting Information.

The signal of the $\mathrm{C}-2-\mathrm{H}$ hydrogen atom of the imidazolium ring is shifted by $2.3 \mathrm{ppm}$ to higher field in [HMIM] $\left[\mathrm{Br}_{9}\right]$ as compared to [HMIM]Br. This indicates a significantly weaker interaction of the cation with the anion $\left[\mathrm{Br}_{9}\right]^{-}$than with $\mathrm{Br}^{-}$as it is expected. This chemical shift of the proton in $\mathrm{C}-2$ position is in the same order of magnitude as it is found for $[\mathrm{HMIM}]^{+}$salts with the anions $\left[\mathrm{NTf}_{2}\right]^{-}\left(\left[\mathrm{NTf}_{2}\right]^{-}=\right.$ bis(trifluoromethylsulfonyl)imide) and $\left[\mathrm{Al}(\mathrm{hfip})_{4}\right]^{-}$ (hfip = hexafluoroisopropoxy) $\quad(\delta=8.61 \mathrm{ppm}$ for [HMIM] $\mathrm{NTf}_{2}$ ] in $\mathrm{CD}_{2} \mathrm{Cl}_{2}$ [22] and $\delta=8.62 \mathrm{ppm}$ for [HMIM][Al(hfip) $)_{4}$ in $\mathrm{CDCl}_{3}$ [23]), which are typical weakly coordinating anions.

\section{Conclusion}

In conclusion, we report herein the first preparation of a room-temperature liquid polybromide monoan- 
ion salt stabilized by an imidazolium cation, namely [HMIM] $\left[\mathrm{Br}_{9}\right]$. Based on its melting point of approximately $-35^{\circ} \mathrm{C}$, and together with its relatively low vapor pressure if compared with neat bromine we can formally describe this new substance as a roomtemperature ionic liquid.

The title compound was investigated by Raman spectroscopy and single-crystal X-ray diffraction. Beyond this, its conductivity was measured and fitted by the Arrheniuns and VFT-approach. Its electrical conductivity is very high and amounts to $52.1 \mathrm{mS}$ $\mathrm{cm}^{-1}$ already at $25.6^{\circ} \mathrm{C}$. In agreement with this high conductivity, NMR measurements using the Spange approach revealed that through coordination of $\mathrm{Br}_{2}$ molecules, the nature of the $\mathrm{Br}^{-}$ion in the $\left[\mathrm{Br}_{9}\right]^{-}$ salt has changed from strongly to weakly coordinating as in salts with typical WCAs like [HMIM] $\left[\mathrm{NTf}_{2}\right]$ or $[\mathrm{HMIM}]\left[\mathrm{Al}(\mathrm{hfip})_{4}\right]$. The liquid nature at room temperature of this new ionic liquid suggests its application as a liquid electrode. Further investigations on related substances are ongoing in our laboratories in Freiburg and Berlin.

\section{Experimental Section}

All experiments were performed using standard Schlenk techniques. The FT-Raman spectra were recorded on a Bruker Vertex 70 spectrometer equipped with a RAM II module using a liquid nitrogen-cooled Ge detector. Raman spectra were recorded (backscattering mode) at room temperature as well as with cooling to liquid nitrogen temperature in flame-sealed glass capillaries $(1064 \mathrm{~nm}, 10 \mathrm{~mW}$ power, resolution $4 \mathrm{~cm}^{-1}$ ).

Conductivity measurements have been performed with the S30 SevenEasy instrument from Mettler Toledo using a platinum electrode InLab710 with a cell constant of $0.8096 \mathrm{~cm}^{-1}$ in a cell filled with $3.5 \mathrm{~mL}$ of the sample.

NMR data were recorded at room temperature on a Bruker DPX 200 spectrometer using the software TOPSPIN 1.3. The samples of the investigated ILs were measured without lock substance. The field was adjusted to the sample of [HMIM] $\left[\mathrm{Br}_{9}\right]$, and the shims were not changed for the sample of [HMIM]Br, which shows broad signals anyway because of its high viscosity at room temperature. To make sure that the field drift can be neglected, both samples were measured directly one after the other with one single scan for each ${ }^{1} \mathrm{H}$ NMR spectrum. For calibration a small amount of TMS was added to the sample of [HMIM] $\left[\mathrm{Br}_{9}\right]$, and the proton chemical shifts detected in these two samples are given with respect to TMS in [HMIM] $\left[\mathrm{Br}_{9}\right]$.
1-Hexyl-3-methylimidazolium nonabromide ([HMIM][Brg]) (1)

By adding or condensing bromine (Merck) to 1-hexyl3-methylimidazolium bromide at the molar ratio of $5: 1$, brownish-red solutions were obtained. After keeping the reaction mixture at $-40{ }^{\circ} \mathrm{C}$ for several days under argon atmosphere brownish red, adhesive crystals of [HMIM] $\left[\mathrm{Br}_{9}\right]$ were formed. From visual judgements, the melting point of this salt is around $-35{ }^{\circ} \mathrm{C}$. Due to its corrosive nature and incompatibility with the $\mathrm{Al}$ crucibles, DSC experiments and thus an exact determination of the melting point was not possible.

[HMIM]Br was dried under vacuum $\left(1 \times 10^{-3} \mathrm{mbar}\right)$ for $16 \mathrm{~h}$ at $80^{\circ} \mathrm{C}$ and stored in an argon glove box. The $[\mathrm{HMIM}]\left[\mathrm{Br}_{9}\right]$ was prepared from $10.00 \mathrm{~g}(0.04 \mathrm{~mol})$ [HMIM]Br on which $32.43 \mathrm{~g}(10.4 \mathrm{ml}, 0.20 \mathrm{~mol})$ neat bromine was added dropwise over $3 \mathrm{~h}$ under stirring. After all the bromine was added, the reaction mixture was stirred a further $72 \mathrm{~h} .-{ }^{1} \mathrm{H}$ NMR data for [HMIM] $\left[\mathrm{Br}_{9}\right.$ ]: $\delta=8.43(1 \mathrm{H}, \mathrm{H}-2, \mathrm{br}), 7.44(1 \mathrm{H}, \mathrm{H}-5, \mathrm{t}), 7.42(1 \mathrm{H}, \mathrm{H}-4, \mathrm{t})$, $4.27(2 \mathrm{H}, \mathrm{H}-6, \mathrm{~m}), 4.07$ (3H,H-1, m), $2.00(2 \mathrm{H}, \mathrm{H}-7, \mathrm{~m}), 1.38$ $(6 \mathrm{H}, \mathrm{H}-8,9,10, \mathrm{~m}), 0.90(3 \mathrm{H}, \mathrm{H}-11, \mathrm{~m}) .-{ }^{1} \mathrm{H}$ NMR data for [HMIM]Br: $\delta=10.8(1 \mathrm{H}, \mathrm{H}-2, \mathrm{br}), 9.03(1 \mathrm{H}, \mathrm{H}-5, \mathrm{br}), 8.95$ $(1 \mathrm{H}, \mathrm{H}-4, \mathrm{~m}), 5.0(2 \mathrm{H}, \mathrm{H}-6, \mathrm{~m}), 4.7(3 \mathrm{H}, \mathrm{H}-1, \mathrm{~m}), 2.4(2 \mathrm{H}$, H-7, m), 1.7 (6H, H-8,9,10, m), 1.2 (3H, H-11, m).

Crystal structure determination of [HMIM][Brg] (1)

$\mathrm{C}_{10} \mathrm{H}_{19} \mathrm{Br}_{9} \mathrm{~N}_{2}, \quad M_{\mathrm{w}}=886.46$, orthorhombic, space group $P 2{ }_{1} 2_{1} 2_{1}, \quad a=8.6452(5) \AA, \quad b=16.0882(9) \AA$, $c=16.6066(9) \AA, \quad V=2309.7(2) \AA^{3}, \quad Z=4$, $\rho_{\text {calcd. }}=2.55 \mathrm{Mg} \mathrm{m}^{-3}, F(000)=1632 \mathrm{e}, \lambda=0.71073 \AA$, $T=100(2) \mathrm{K}$, absorption coefficient $=15.6 \mathrm{~mm}^{-1}$, absorption correction: multi-scan, $T_{\min }=0.2546, T_{\max }=0.7456$. Data for the structure determination were collected on a Bruker SMART APEX2 CCD area detector diffractometer with $\mathrm{Mo} K_{\alpha}$ radiation. A single crystal was taken directly from the reation mixture, coated at $-40{ }^{\circ} \mathrm{C}$ with perfluoroether oil and mounted on a $0.1 \mathrm{~mm}$ Micromount. The structure was solved by Direct Methods with SHELXTL [24] and OLEX2 [25] and refined by least-squares on weighted $F^{2}$ values for all reflections. The final refinements converged at $\mathrm{GooF}=1.043, R 1=0.0263$ and $\mathrm{w} R 2=0.0608$ for reflections with $I>2 \sigma(I)$ and $R 1=0.0304$ and $\mathrm{w} R 2=0.0621$ for all reflections. The hydrogen atoms were included in the refinement in calculated positions by a riding model. The graphical representations were prepared with DIAMOND [26].

CCDC 941404 contains the supplementary crystallographic data for this paper. These data can be obtained free of charge from The Cambridge Crystallographic Data Centre via www.ccdc.cam.ac.uk/data_request/cif. 
In addition, tables of the crystal data, atomic coordinates including hydrogen atoms, displacement parameters and important bond lengths and angles are given in the Supporting Information.

\section{Supporting information}

Figures of the Raman and ${ }^{1} \mathrm{H}$ NMR spectra and tables containing the numerical values of the conductivity measurements and the NMR spectra as well as addditional crystal structure data are given as Supporting Information available online (DOI: 10.5560/ZNB.2013-3143).

\section{Acknowledgement}

The authors are grateful to Alexander Rupp for stimulating discussions. This work was supported by the University of Freiburg, the Fonds der Chemischen Industrie and the ERC UniChem-project.
[1] K. N. Robertson, P. K. Bakshi, T. S. Cameron, O. Knop, Z. Anorg. Allg. Chem. 1997, 623, 104.

[2] C. W. Cunningham, G. R. Burns, V. McKee, Inorg. Chim. Acta 1990, 167, 135.

[3] M. Wolff, J. Meyer, C. Feldmann, Angew. Chem. Int. Ed. 2011, 50, 4970.

[4] D. Freudmann, S. Wolf, M. Wolff, C. Feldmann, Angew. Chem. Int. Ed. 2011, 50, 11050.

[5] N. Bricklebank, P. J. Skabara, D. E. Hibbs, M. B. Hursthouse, K. M. Abdul Malik, J. Chem. Soc., Dalton Trans. 1999, 3007.

[6] M. C. Aragoni, M. Arca, F. A. Devillanova, M. B. Hursthouse, S. L. Huth, F. Isaia, V. Lippolis, A. Mancini, H. Ogilvie, Inorg. Chem. Commun. 2005, 8, 79.

[7] M. C. Aragoni, M. Arca, F. A. Devillanova, F. Isaia, V. Lippolis, A. Mancini, L. Pala, A. M. Z. Slawin, J. D. Woollins, Chem. Commun. 2003, 2226.

[8] K. O. Stroemme, Acta Chem. Scand. 1959, 13, 2089.

[9] G. L. Breneman, R. D. Willett, Acta Crystallogr. 1967, $23,334$.

[10] D. Freudenmann, S. Wolf, M. Wolff, C. Feldmann, Angew. Chem. Int. Ed. 2011, 50, 11050.

[11] H. Haller, M. Ellwanger, A. Higelin, S. Riedel, Angew. Chem. Int. Ed. 2011, 50, 11528.

[12] H. Haller, S. Riedel, Nachr. Chem. 2012, 9, 865.

[13] H. Haller, M. Ellwanger, A. Higelin, S. Riedel, Z. Anorg. Allg. Chem. 2012, 638, 553.

[14] M. Wolff, A. Okrut, C. Feldmann, Inorg. Chem. 2011, 50,11683 .
[15] V. Vitske, H. Herrmann, M. Enders, E. Kaifer, H.-J. Himmel, Chem. Eur. J. 2012, 18, 14108.

[16] H. Haller, J. Schröder, S. Riedel, Angew. Chem. Int. Ed. 2013, 52, 4937.

[17] K. P. Huber, G. Herzberg, Molecular Spectra and Molecular Structure, 4: Constants of Diatomic Molecules, Van Nostrand, New York, 1979.

[18] S. Bulut, P. Eiden, W. Beichel, J. M. Slattery, T. F. Beyersdorff, T. J. S. Schubert, I. Krossing, ChemPhysChem 2011, 12, 2296.

[19] P. Eiden, S. Bulut, T. Kochner, C. Friedrich, T. Schubert, I. Krossing, J. Phys. Chem. B 2011, 115, 300.

[20] I. Rubinstein, M. Bixon, E. Gileadi, J. Phys. Chem. 1980, 84, 715.

[21] R. Lungwitz, S. Spange, ChemPhysChem 2012, 13, 1910

[22] S. Pitula, Dissertation, Universität zu Köln, Köln 2009.

[23] S. Bulut, P. Klose, M.-M. Huang, H. Weingärtner, P. J. Dyson, G. Laurenczy, C. Friedrich, J. Menz, K. Kümmerer, I. Krossing, Chem. Eur. J. 2010, 16, 13139.

[24] G. M. Sheldrick, Acta Crystallogr. 2008, A64, 112.

[25] O. V. Dolomanov, L. J. Bourhis, R. J. Gildea, J. A. K. Howard, H. Puschmann, J. Appl. Crystallogr. 2009, 42, 339.

[26] K. Brandenburg, DiAmond (version 3.1), Crystal and Molecular Structure Visualization, Crystal Impact - K. Brandenburg \& H. Putz GbR, Bonn (Germany) 2009. See also: http://www.crystalimpact.com/ diamond/. 